\title{
INFLLENCE OF PHYSICAL ACTIVITY ON REDUCTION OF DELAYED ONSET MUSCLE SORENESS
}

\author{
Dariusz Boguszewski, , A, B, C, D, E Beata Oko,, B, D Sylwia Szkoda,, B, D \\ Jakub Grzegorz Adamczyk, ${ }^{1,2, C, D, E}$ Dariusz Białoszewski' D, E
}

\footnotetext{
1 Department of Rehabilitation, Physiotherapy Division. Medical University of Warsaw, Poland

2 Department of Theory of Sport. Józef Piłsudski University of Physical Education in Warsaw, Poland

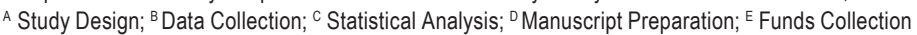

\author{
Address for correspondence: \\ Dariusz Boguszewski \\ Medical University of Warsaw \\ Rehabilitation Department, Physiotherapy Division \\ Żwirki i Wigury 81, 02-091 Warsaw, Poland \\ E-mail: dboguszewski@wum.edu.pl
}

\begin{abstract}
Ahstract. The purpose of this study was to determine if physical activity of different intensity has an effect on reduction of delayed onset muscle soreness. Eighty women divided into two groups participated in the study. Subjects from Group 1 participated in the training of upper libs, whereas subjects from group 2 - in the training of lower limbs. Tests of power of upper limbs - the active overhang on the bar (Gr. 1) and power of lower limbs - the vertical jump test (Gr. 2), visual analog scale of pain (VAS) and the International Physical Activity Questionnaire (IPAQ) were used as investigative tools. The majority of studied women were characterized by the high level of physical activity. Physical activity level had strong positive correlation $(r=0.54 ; p<0.001)$ with the reduction of pain. Taking into account the partition according to the kind of physical activity, there was observed some significant correlation between the diminution of delayed onset muscle soreness and the level of moderate activity and walking (relocating). Physical activity level positively correlated with the reduction of delayed onset muscle soreness. Moderate physical activity and walking proved to be the most beneficial from the reduction of delayed onset muscle soreness point of view.
\end{abstract}

Key WOrll: DOMS, physical activity, post-exercise recovery, muscle damage, IPAQ

\section{Introduction}

Delayed onset muscle soreness, in short DOMS, is developed usually from several to a dozen or so hours after the intense exercise. Its culminant intensity appears between the second and the third day after the activity and can last even for 5-7 days. Most often it occurs in people not practicing sport, who proceeded with physical effort of greater intensity than activities performed on an everyday basis and at sportsmen who return to trainings after a long break. Greater threat with the damage of fibers is caused by the eccentric exercises because, in their 
progress, the tension per motor unit is far higher than during concentric efforts (Wilmore and Costill 2004; Czarkowska-Pączek and Przybylski 2006).

The effect of delayed onset muscle soreness on physical activity is not fully explained. It is accepted that it is characterized by the fall of muscular power, limitation of mobility in joints and disturbances of co-ordination of motor units' muscles during their contraction. Too early renewal (repetition) of the training can be connected with the activation of compensatory mechanisms of above-disturbances, and what is more, with the risk of repeated damage of tissues. On the other hand the repetition of exercises of similar character leads to organism's adaptation and contributes to diminution of damages extensiveness and myalgia (Bednarek et al. 2013; Augustyn et al. 2013; Halson 2008).

In the counteraction of DOMS results different strategies of conduct are proposed, however, their efficiency is not always confirmed, some of them are not effective (Punduk et al. 2014). As Cheung et al. (2003) suggest non-steroidal anti-inflammatory medicines are of high efficiency. Massage gives diverse effects (depending on the length of application and put-upon techniques). Zainuddin et al. (2005) suggest that the massage can lower pain complaints by about $30 \%$, but it does not influence functions of the muscle. In turn, the efficiency of stretching, local cryotherapy, homeopathy and ultrasounds is limited. It is also shown that moderate physical activity is the most efficient kind of conduct during the occurrence of DOMS symptoms, though its effect can be temporary (Cheung et al 2003). The influence on the previously mentioned temporary analgesic effect can be the reason here, despite the lack of influence on the renovation of muscles after micro damages (Zainuddin et al. 2006). What is more, badly chosen conduct, despite the immediate analgesic effect can outright retard the full restoration of muscle structure (Coudreuse et al. 2004).

In the absence of univocal evidence of influence of the physical exercise of given intensity on DOMS, the main cognitive objective of this study was the estimation of influence of different intensity physical activity on reduction of delayed onset muscle soreness of upper and lower limbs.

\section{Material and methods}

There were 80 women, aged 18-28 years, not attending any organized sports or recreational activities, who partook in the research. The subjects were randomly divided into two groups. Group 1 consisted of women who had the training of upper limbs applied. Group 2 comprised of participants who participated in the training of lower limbs. Groups did not significantly differ in respect of the age and body mass or height (Table 1). The research was not-invasive and the approval of the Bioethics Committee of Medical University of Warsaw was not required.

Table 1. Research group profile

\begin{tabular}{cccccc}
\hline \multicolumn{1}{c}{ Groups } & $\begin{array}{c}\text { Number of people } \\
{[\mathrm{n}]}\end{array}$ & $\begin{array}{c}\text { Age } \\
{[\text { years }]}\end{array}$ & $\begin{array}{c}\text { Body mass } \\
{[\mathrm{kg}]}\end{array}$ & $\begin{array}{c}\text { Body height } \\
{[\mathrm{cm}]}\end{array}$ & $\begin{array}{c}\text { BMl } \\
{\left[\mathrm{kg} / \mathrm{m}^{2}\right]}\end{array}$ \\
\hline Group 1 (training of upper limbs) & 40 & $22.03 \pm 2.62$ & $56.23 \pm 5.56$ & $167.93 \pm 5.29$ & $19.91 \pm 1.82$ \\
Group 2 (training of lower limbs) & 40 & $24.68 \pm 1.07$ & $57.3 \pm 4.99$ & $165.9 \pm 5.12$ & $20.85 \pm 1.91$ \\
\hline
\end{tabular}

All women taking part in the research were interviewed before participating in the study. The questionnaire referred to present diseases of circulatory system, respiratory system and past traumas within upper/lower limbs 
and the spine, making the execution of tests impossible. Women not burdened with above-mentioned diseases and trauma qualified to the research.

Women from Group 1 were subjected to test of power of shoulders (measurement 1), which was an active overhang on a bar, and then there was a training of shoulder muscles. It consisted of series of minimum five active overhangs - similarly as during the test, during 60 to $80 \%$ of the first test (i.e. the time of maximum ability). Every series was finished with a rest of the time equal to minimum twice the time of the overhang. Women from Group 2 performed the test of power of lower limbs, which was a vertical jump (measurement 1 ) and the training of lower limbs muscles in five series of squat jumps of $60-100 \%$ of maximum abilities (the first series till the refusal, series $2-4$ of $60-80 \%$ ability, the fifth series till the refusal). After the training both groups had the measurement of pain intensity taken (measurement 1). Then tests of shoulders power (Group 1) and powers of lower limbs (Group 2) were repeated and the level of pain intensity was rated (visual analog scale of pain - VAS) after 24 (measurement 2), 48 (measurement 3), 72 (measurement 4) and 96 hours (measurement 5).

To estimate the efficiency of muscles burdened with the training tests of physical fitness were applied, for Group 1 - the test of power of shoulders (from the International Physical Fitness Test) consisting of the active overhang on the bar, (where the result was determined by the time of holding in the overhang, with the head above the bar) and for Group 2 - the test of power of lower limbs (the vertical jump), consisting of the squat jump - (where the result was determined by the height of lifting of the center of gravity) (Bielski 1996). The intensity of the pain was rated with the use of visual analog scale - VAS (Korzeniowska and Szałek 2010). Reduction of pain was established by the difference between maximal intensity of pain and value obtained in the last measurement.

For the purpose of qualifying the level of physical activity, the researched women filled, on the last day of the research (96 hours after the training), the International Physical Activity Questionnaire - the short version, consisting of seven questions. They referred to undertaken activity in last seven days. The physical activity level was rated in three categories (vigorous, moderate and walking). The result is expressed in agreed upon MET estimates (IPAQ 2012; Biernat et al. 2008).

Standard statistical tools such as the arithmetical mean together with the standard deviation were used in the research. Differences between performances of each measurement were counted by means of paired t-Student test and dependences between the variable were estimated by means of Pearson correlation. Level $p \leq 0.05$ was accepted as of minimum significance.

\section{Results}

The greatest regress of agility test data $(p<0.001)$, in both groups, was noted between the first and the second measurement ( 24 hours after the exercise). Progress of results was observed instead between the fourth and the fifth measurement (in Group 1 the difference was statistically significant $p<0.001$ ). In Group 1 the result of the last test was indeed higher than of the first one. In Group 2 results of the first and last test were similar (Figure 1).

The highest level of pain (measured with the VAS) was noted in the third measurement, which took place 48 hours after the exercise, both in women realizing the training of upper limbs, as well as the lower ones. On the following days (measurement 4 and 5 ) the intensity of complaint was indeed lower $(p<0.001)$ in both groups. People from Group 2 were characterized by the lower average level of pain in all five measurements (Figure 2). 


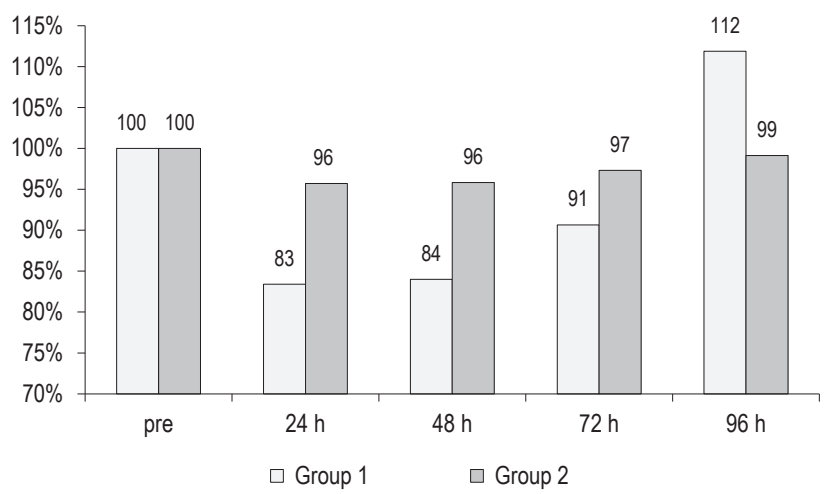

Figune 1. Results of physical fitness tests (of upper limbs - Groups 1 and lower limbs - Groups 2).

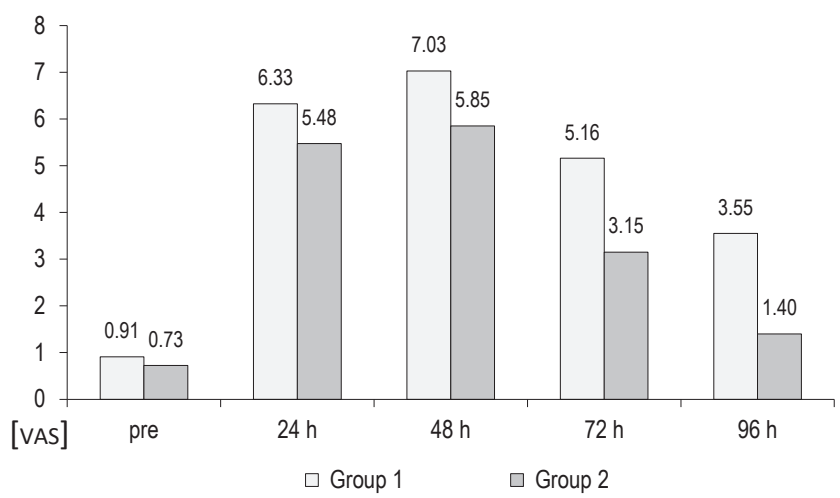

Figule 2. Intensity of muscle pain

The majority of researched women (20 from Group 1 and 24 from Group 2) were characterized by the high level of physical activity, IPAQ measured. To the category of sufficient physical activity 29 were classified (18 from Group 1 and 11 from Group 2), and to inadequate - 7 women (2 from Group 1 and 7 from Group 2). The average level of general physical activity was similar in both groups. The significant difference $(p<0.001)$ was noted only with reference to vigorous physical activity (Table 2).

Tahle 2. Level of physical activity measured by IPAQ

\begin{tabular}{lccccc} 
& $\begin{array}{c}\text { Vigorous physical activity } \\
{[M E T]}\end{array}$ & $\begin{array}{c}\text { Moderate physical activity } \\
{[\text { [MET] }}\end{array}$ & $\begin{array}{c}\text { Walking } \\
{[\text { MET] }}\end{array}$ & $\begin{array}{c}\text { Sitting } \\
{[\text { min. per day] }}\end{array}$ & $\begin{array}{c}\text { Sum } \\
{[M E T]}\end{array}$ \\
\hline Group 1 & $959^{*+*} \pm 971$ & $1019 \pm 1691$ & $1851 \pm 1443$ & $327 \pm 338$ & $3829 \pm 3040$ \\
Group 2 & $282 \pm 451$ & $1374 \pm 1197$ & $2131 \pm 1988$ & $321 \pm 245$ & $3788 \pm 2554$ \\
\hline
\end{tabular}

${ }^{* * *} p<0.001$. 
The physical activity level measured with IPAQ, expressed in MET estimates, strongly and positively correlated $(r=0.54 ; p<0.001$ ) with the reduction of pain (with the difference between the maximum and minimum-level of pain measured with the VAS) (Figure 3). Taking into account the partition according to the kind of physical activity, some important correlation between the diminution of delayed onset soreness of burdened muscles and the level of moderate activity and walking was observed. Similar dependences were not observed in the case of vigorous activity and akinesis (Table 3).

There were no significant correlations between the level of physical activity and fitness tests.

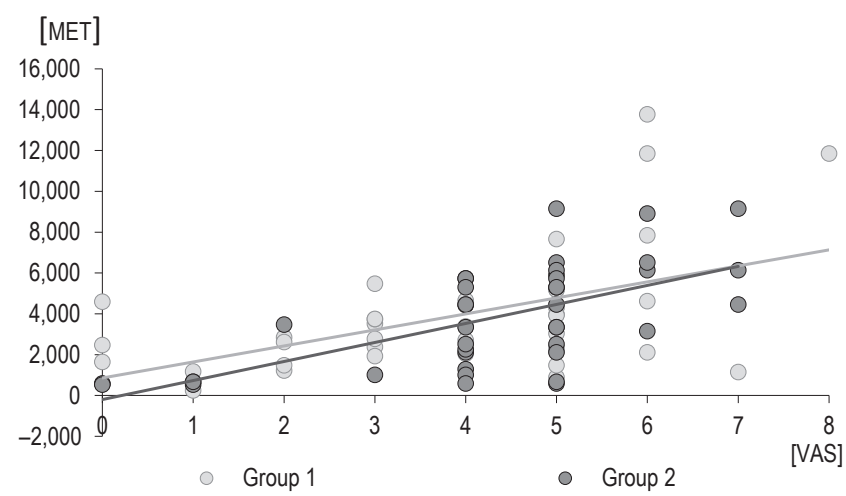

Figule 3. Correlation between reduction of pain and overall physical activity

Tahle 3. Correlation between reduction of pain and physical activity

\begin{tabular}{lccccc}
\cline { 2 - 5 } & $\begin{array}{c}\text { Vigorous physical } \\
\text { activity }\end{array}$ & $\begin{array}{c}\text { Moderate physical } \\
\text { activity }\end{array}$ & Walking & Sitting & Sum \\
\hline Group 1 & -0.052 & $0.471^{* *}$ & $0.537^{* * *}$ & 0.057 & $0.500^{* * *}$ \\
Group 2 & 0.105 & $0.514^{*+*}$ & $0.481^{* *}$ & -0.292 & $0.634^{*+*}$ \\
\hline
\end{tabular}

${ }^{* *} p<0.01 ;{ }^{* * *} p<0.001$.

\section{Discussion}

The occurrence of muscular fatigue has a composite basis conditioned with the kind of physical activity. Mechanisms concerning its formation differ depending on types of muscle fibers. Exercises with a component of eccentric contractions generate greater power in comparison to concentric and isometric types; moreover, it correlates with smaller and later fatigue with relation to remaining two kinds of exercises (Wilmore and Costill 2004; Czarkowska-Pączek and Przybylski 2006).

The genesis of delayed muscle soreness was not exactly proved, however there are several opinions on the subject. It was assumed that it was related to too high level of injurious metabolites in skeletal muscles - especially the lactate. The lack of correlation in time of both from these factors caused challenging of this assumption (Wilmore 
and Costill 2004; Bednarek et al. 2013). Among many authors there is a conviction that the reason of DOMS is multifaceted. The starting point of its appearance is the inflammation in response to the microdamage of muscle fibers, during the eccentric physical exercise. Symptoms that accompany the inflammation (i.e. the swelling and pyrexia of tissues) increase sensation of pain in muscles. In turn, the level drop of calcium in endoplasmic reticulum and the inflammatory swelling of tissues lead to the stiffness of muscles felt after finished physical activity. Prostaglandins, which are chemical mediators of the inflammation, among other things, are responsible for this mechanism. As the result of lowered level of nociception in muscles, strong sensation of pain is observed in response to occurring mechanical impulse - e.g. the muscle contraction (Bednarek et al. 2013; Augustyn et al. 2013; Halson 2008).

Some interest in methods of aiding post-exercise biological renovation and reduction of delayed onset muscle soreness can be noticed in the available literature, especially in the area of sports-medicine (Best et al. 2008; Lee et al. 2013; Bae et al. 2014). Kawczyński et al. (2013), studying football competitors before the game and after it, showed the differentiation of DOMS symptoms of dominating and non-dominating lower limb muscles. Results of this research suggest the variability of the occurrence of DOMS symptoms, for the dominating side of body, despite the use of similar physical effort (Kawczyński et al. 2013).

To improve the post-exercise restitution and minimization of DOMS symptoms several physiotherapeutic applications were used. Classical massage was most often used. Its beneficial effect on delayed onset muscle soreness e.g. of biceps of shoulder and quadriceps of thigh (burdened by participants of own research) is confirmed. Massage was not only analgesic, but it also considerably accelerated the restoration of tired muscles efficiency (Willems et al. 2009; Boguszewski et al. 2013; 2014).

Results of Lee's et al. (2013) research, with reference to manners of DOMS minimization, gave some interesting information. In this research speed of the reduction of DOMS symptoms at women and men were compared, referring at this to the risk of $A C L$ injury. Authors subjected the estimation of the ligament elasticity before and during the occurrence of DOMS symptoms. On the ground of results obtained, authors suggest that women are more subject to injury of anterior cruciate ligament and they return to full efficiency after exercises more slowly. Therefore, thesis was put forward, that in women the time of convalescence after the hard physical exercise is prolonged (Lee et al. 2013).

Bae et al. (2014) evaluated the influence of kinesiology taping (KT) on the reduction of delayed onset muscle soreness of shoulder biceps. Based on the thermal result the of the pain level, it was observed, that pain complaints diminished considerably in the researched group after 24 hours from the exercise. Quicker decrease of pain in the group with the KT application was noted. The researchers suggest that KT causes subjective diminution of pain (Bae et al. 2014).

Own research proved that active rest, even without the use of physiotherapeutic applications, could accelerate the post-exercise regeneration. From the practical point of view, combination of different means of renovation seems to be the best solution. Research carried out by Imtiyaz et al. (2014) confirms beneficial influence of vibratory training combined with massage. According to the researchers, the application of massage helps more quickly to restore the muscles power (which were earlier subjected to exercise), and the vibration of muscles causes earlier minimization of pain in comparison to control group (Imtiyaz et al. 2014).

There is no sufficient evidence to prove the efficiency of different kinds of therapy on DOMS reduction. Due to different investigative tools used in research, it is difficult to compare the results. Proper and new manners 
of treatment and rehabilitation of diseases and dysfunctions (in compliance with foundations of Evidence-Based Medicine) are constantly being sought after. It seems legitimate to continue the research on DOMS phenomenon and efficiency of different means of post-exercise renovation.

\section{Conclusions}

1. Physical activity level positively correlated with the reduction of post-exercise muscle soreness. This confirms the beneficial influence of active rest even after very burdening eccentric exercises.

2. Moderate physical activity and walking proved to be the best in relation to reduction of delayed onset muscle soreness. Exercise of little intensity can be one of biological rejuvenation elements.

3. Obtained results are basis for continuation of research (with the use of other investigative tools) with the participation of more diverse experimental groups.

\section{Acknowledgements}

The authors would like to thank the volunteers who took part in this study.

\section{References}

Augustyn G., Wodnicka A., Szyguła Z. The influence of stretching on delayed onset of muscle soreness. Medicina Sportiva Practica. 2013; 14 (4): 97-99.

Bae S.H., Lee Y.S., Kim G.D., Kim K.Y. A quantitative evaluation of delayed onset muscular soreness according to application of Kinesio Taping. Advanced Science and Technology Letters. 2014; 47: 387-390.

Bednarek J., Kępińska M., Augustyn G., Szyguła Z. Fatigue and overtraining - an overview of the problem. Medicina Sportiva Practica. 2013; 14 (3): 83-88.

Best T.M., Hunter R., Wilcox A., Haq F. Effectiveness of sports massage for recovery of skeletal muscle from strenuous exercise. Clinical Journal of Sport Medicine. 2008; 18 (5): 446-460.

Bielski J. Life is movement. Guidebook for PE teachers. Promo-Lider, Warszawa 1996.

Biernat E., Stupnicki R., Lebiedziński B., Janczewska L. Assessment of physical activity by applying IPAQ questionnaire. Physical Education and Sport. 2008, 52: 46-52.

Boguszewski D., Poświata P., Oko B., Osipiuk S., Adamczyk J.G., Białoszewski D. Assessment of sports massage effectiveness in reduction of delayed onset muscle soreness of biceps brachii. Polish J Sport Med. 2013; 29 (4): 215-221.

Boguszewski D., Szkoda S., Adamczyk J.G., Białoszewski D. Sports massage therapy on the reduction of delayed onset muscle soreness of the quadriceps femoris. Human Movement. 2014, 15 (4): 234-237.

Cheung K., Hume P., Maxwell L. Delayed onset muscle soreness : treatment strategies and performance factors. Sports Med. 2003; 33 (2): 145-164.

Coudreuse J.M., Dupont P., Nicol C. Delayed post effort muscle soreness. Ann Readapt Med Phys. 2004 Aug; 47 (6): 290-298.

Czarkowska-Pączek B., Przybylski J. Zarys fizjologii wysiłku fizycznego. Elsevier Urban \& Partner, Wrocław 2006.

Halson S.L. Nutrition, sleep and recovery. European Journal of Sport Science. 2008; 8 (2): 119-126.

Imtiyaz S., Veqar Z., Shareep M.Y. To compare the effect of vibration therapy and massage in prevention of delayed onset muscle soreness (DOMS). Journal of Clinical and Diagnostic Research. 2014; 8 (1): 133-136.

International Physical Activity Questionnaire, www.ipaq.ki.se/ipaq.htm (17.07.2012).

Kawczyński A., Mroczek D., Chmura P., Madeleine P., Chmura J. Influence of a professional football game on delayed onset muscle soreness development in dominant and non-dominant legs. Polish J Sport Med. 2013; 29 (1): 55-61.

Korzeniowska K., Szałek E. The pain. Farm Wspol. 2010; 3: 9-14.

Lee H., Petrofsky J.S., Laymon M., Yim J. A Greater Reduction of Anterior Cruciate Ligament Injury in Women Compared to Men as a Result Delayed Onset Muscle Soreness. The Thoku Journal of Experimental Medicine. 2013; 231: 111-115. 
Punduk Z., Oral O., Aydinoglu R., Ozkayin N. Exercise induced muscle damage may be improved by a single dose of intra-muscular platlet rich plasma: A Pilot Study. Centr Eur J Sport Sci Med. 2014; 8 (4): 19-26.

Willems M.E.T., Hale T., Wilkinson C.S. Effects of manual massage on muscle specific soreness and single leg jump performance after downhill treadmill walking. Medicina Sportiva. 2009; 13 (2): 61-66.

Wilmore J.H., Costill D.L. Physiology of sport and exercise. Human Kinetics, Champaign 2004.

Zainuddin Z., Newton M., Sacco P., Nosaka K. Effects of massage on delayed-onset muscle soreness, swelling, and recovery of muscle function. J Athl Train. 2005 Jul-Sep; 40 (3): 174-180.

Zainuddin Z., Sacco P., Newton M., Nosaka K. Light concentric exercise has a temporarily analgesic effect on delayed-onset muscle soreness, but no effect on recovery from eccentric exercise. Appl Physiol Nutr Metab. 2006 Apr; 31 (2): 126-134.

Cite this article aS: Boguszewski D., Oko B., Szkoda S., Adamczyk J.G., Białoszewski D. Influence of Physical Activity on Reduction of Delayed Onset Muscle Soreness. Central European Journal of Sport Sciences and Medicine. 2015; 12 (4): 83-90. 